\title{
Allelopathic Effects of Cinnamomum migao on Seed Germination and Seedling Growth of its Associated Species Liquidambar formosana
}

\author{
Deng Wang, Jingzhong Chen, Xue Xiong, Shu Wang and Jiming Liu * \\ College of Forestry, Guizhou University, Guiyang 550025, China \\ * Correspondence: Karst0623@163.com; Tel.:+86-13985015398
}

Received: 23 May 2019; Accepted: 21 June 2019; Published: 26 June 2019

\begin{abstract}
We examined allelopathic effects and underlying mechanisms of Cinnamomum migao on its associated species Liquidambar formosana. We assessed effects of aqueous extracts of $C$. migao pericarp, leaf, and rhizosphere soil at different concentrations on seed germination, seedling growth, and physiology of L. formosana. All extracts inhibited L. formosana seed germination, with obvious inhibition at high concentrations $\left(50 \mathrm{mg} \mathrm{mL}^{-1}\right)$. All extracts promoted the height and ground diameter of seedlings, with the highest promotion achieved with aqueous leaf extract at a concentration of $1 \mathrm{mg}$ $\mathrm{mL}^{-1}$ and aqueous pericarp and rhizosphere soil extracts at a concentration of $5 \mathrm{mg} \mathrm{mL}^{-1}$. All extracts promoted soluble protein accumulation in L. formosana seedlings, with the highest accumulation achieved with aqueous pericarp extracts. Aqueous leaf extract promoted soluble starch accumulation. Aqueous pericarp extract at concentrations of $>10 \mathrm{mg} \mathrm{mL}^{-1}$ significantly increased soluble sugar content. Aqueous leaf and rhizosphere soil extracts at concentrations of $>5 \mathrm{mg} \mathrm{mL}^{-1}$ increased proline accumulation. All extracts at concentrations of $>1 \mathrm{mg} \mathrm{mL}^{-1}$ significantly increased malondialdehyde content. Aqueous pericarp and rhizosphere soil extracts at concentrations of 10 and $0.5 \mathrm{mg} \mathrm{mL}^{-1}$, respectively, promoted superoxide dismutase activity. Activities of soil urease, polyphenol oxidase, and catalase were significantly increased when the concentration of aqueous pericarp and leaf extracts exceeded $5 \mathrm{mg} \mathrm{mL}^{-1}$, and the activity of soil acid phosphatase significantly increased when the concentration of all extracts were $5 \mathrm{mg} \mathrm{mL}^{-1}$. According to the synthetic allelopathic index, the lowand medium-concentration extracts all showed a promoting effect, whereas high concentrations exhibited obvious inhibitory effects; furthermore, the comprehensive effect value of leaf water extraction was higher than that of the pericarp and rhizosphere soil. Thus, allelopathy can affect the long-term co-existence of C. migao and L. formosana.
\end{abstract}

Keywords: Cinnamomum migao; Liquidambar formosana; associated species; aqueous extracts; allelopathy

\section{Introduction}

Allelopathy is an ecological phenomenon related to the effects of chemicals produced by an organism on the growth, development, and distribution of other plants in natural communities or agricultural systems [1]. Some plants and microorganisms release certain chemicals into the environment through rhizosphere secretion, elution, volatilization, seed germination, and pollination [2]. Allelopathy may be harmful or beneficial. Chemical ecological factors commonly existing in forest ecosystems have a significant impact on the structure, function, efficiency, and development of forest communities [3]. In recent years, the important roles of plant allelopathy in intraspecific and interspecific relationships, community succession, species distribution, and biological invasion [4-7] have garnered much attention, rendering studies on these topics a hotspot of ecological research. Many scholars have conducted extensive studies on mechanisms underlying and factors influencing 
allelochemical activity; roles of allelochemicals in crop plantation, biological invasion, and community succession; and interactions between allelochemicals and soil microorganisms [8-13]. Recent studies have shown that allelochemicals directly or indirectly affect plant growth by affecting somatic cell structure, photosynthesis, antioxidants, osmotic substances, and related enzyme activities [14-19].

In ecological communities, neighbors can directly or indirectly influence the growth and development of one another by coordinating environmental factors, such as forest nutrient conditions, and play a significant role in improving forest vegetation cover, increasing forest vegetation resource reserves, and enhancing physical and chemical properties of surface soil. Currently, most studies on the associative relationships among trees have focused on timber cultivation. These studies have largely focused on means of increasing timber growth rate and yield, such as through co-existence of Calluna vulgaris and other species [20], effects of associated tree species on Pinus tabuliformis growth [21], and effects of the associated tree species Populus tremuloides on Picea Mariana growth in Quebec [22].

Here, we studied the association between Cinnamomum migao and Liquidambar formosana, which are endemic to the karst areas of Southwest China. Both species are medicinal plants. In a previous survey of 13 plots, we observed that the L. formosana communities in C. migao forests were growing well and that the age of trees of both species was more than 50 years, suggesting obvious associative phenomena [23]. Therefore, allelopathy exhibited by one plant could be a critical factor influencing the establishment and survival of another; this is possible mainly due to the influence of allelopathy on seed germination and seedling growth of the other plants in a plant community, further affecting species distribution patterns. In addition to the environmental adaptability of L. formosana, whether allelochemicals of C. migao can promote or inhibit its growth in the course of slow development would influence the stability of L. formosana communities. Numerous phenolic acids and volatile oils have been detected in fruit and leaves of C. migao [24-26]. The essential oils of $C$. migao exert certain inhibitory effects on some microorganisms, and its aqueous extracts show allelopathic effects on Blumea balsamifera [27].

Based on the results of previous studies, we speculated that the allelopathic ability of C. migao is one of the reasons underlying the stability of $C$. migao forests. Therefore, we assessed allelopathic effects of different concentrations of aqueous pericarp, leaf, and rhizosphere soil extracts of $C$. migao on L. formosana. Furthermore, the mechanisms underlying allelopathic effects of $C$. migao extracts on L. formosana seed germination as well as physiological and biochemical indices of seedling growth were discussed. Elucidating physiological mechanisms underlying associative phenomena among species may provide a theoretical basis for revealing the potential associative interactions among species within a community in the future.

\section{Materials and Methods}

\subsection{Study Site}

This study was conducted in a nursery at Guizhou University Southern Campus Forestry College, Huaxi District, Guiyang City $\left(26^{\circ} 34^{\prime} \mathrm{N} 106^{\circ} 42^{\prime} \mathrm{E}\right.$; altitude, $\left.\sim 1020 \mathrm{~m}\right)$. In this region, the average annual temperature, relative humidity, total precipitation are $15.3^{\circ} \mathrm{C}, 77 \%$, and 1129.5 $\mathrm{mm}$, respectively, and average rainfall, sunshine, and snowfall durations are 235.1 days, $1148.3 \mathrm{~h}$, and 11.3 days, respectively.

\subsection{Experimental Design}

From the Luodian County in Guizhou Province, healthy fruit were collected in December 2016 and leaf and rhizosphere soil were collected in May 2017. Pericarps of C. migao fruit were stripped. The rhizosphere soil was collected along the trunks and roots of selected plants in dug ditches. While keeping rhizosphere of the plant intact, small lateral and fibrous roots were collected and the soil between $0-1 \mathrm{~cm}$ of the rhizosphere was gently brushed and collected. Collected soil samples were bagged, transported to the laboratory, air-dried, washed with distilled water, passed through a $0.25 \mathrm{~mm}$ sieve, crushed to fine powder, and stored at $4{ }^{\circ} \mathrm{C}$ until use. Pericarps, leaves, and rhizosphere soil were 
weighed (100 g) and extracted at room temperature in $1000 \mathrm{~mL}$ distilled water for $48 \mathrm{~h}$, during which they were placed on a rotary shaker for 5 min every $12 \mathrm{~h}$, and then centrifuged for $15 \mathrm{~min}$ at $4000 \mathrm{rpm}$. The undiluted extracts with a mass concentration of $100 \mathrm{mg} \mathrm{mL}^{-1}$ were obtained by vacuum filtration. The undiluted extracts were aliquoted into $0,0.5,1,5,10$, and $50 \mathrm{mg} \mathrm{mL}^{-1}$ concentration gradients for biological tests and refrigerated at $4{ }^{\circ} \mathrm{C}$ as a stock.

In December 2016, healthy L. formosana seeds were collected from the Luodian County. The seeds were bagged, transported to the laboratory, air-dried, and rinsed with distilled water. A quantitative Petri dish (diameter, $9 \mathrm{~cm}$ ) was sterilized in an autoclave at $120{ }^{\circ} \mathrm{C}$ for $30 \mathrm{~min}$, and two layers of quantitative filter paper were placed in it. An artificial climate incubator was cleaned and disinfected with $70 \%$ alcohol. A total of 100 seeds of uniform size were placed in each Petri dish, and $5 \mathrm{~mL}$ of test solutions of different concentrations (subject to 1/3rd submergence of seeds) were added. Each treatment was repeated three times. In the artificial climate incubator, the temperature was $25{ }^{\circ} \mathrm{C} \pm 3{ }^{\circ} \mathrm{C}$, humidity was $60 \% \pm 2 \%$, and light/dark conditions were $12 \mathrm{~h}$ each. The corresponding treatment solutions were added daily to keep the dish moist. Germinated L. formosana seeds were counted from the 2nd day after inoculation.

In early April 2017, potted seedlings were raised in a greenhouse in Guizhou University Forestry College, and ramets were planted in May 2017. In June, the cultivated soil was collected from the nursery at Guizhou University Forestry College. After drying, grinding, disinfection, and sterilization, L. formosana seedlings were placed in pots with a bottom diameter of $20 \mathrm{~cm}$ and a depth of $25 \mathrm{~cm}$. L. formosana seedlings of similar height and type were transplanted into flowerpots. Five concentrations $\left(0.5,1,5,10\right.$, and $\left.50 \mathrm{mg} \mathrm{mL}^{-1}\right)$ were used to treat $L$. formosana seedlings, with six replicates per treatment and three seedlings per replicate. After planting for 1 month, the seedlings were treated with $250 \mathrm{~mL}$ aqueous extract from pericarp, leaf, or rhizosphere soil every week after normal growth. The control group (CK) was treated with $250 \mathrm{~mL}$ distilled water for 90 days. During the experiments, no fertilizer was applied, and the seedlings were treated for 1 month. Plants exhibiting similar disease-free growth were selected for experiments.

\subsection{Data Collection}

Germination bioassay: Germination rate was determined as the percentage of germinated seeds per total number of tested seeds, and the germination potential was determined as the percentage of normal germinated seeds per total number of tested seeds within the first 5 days.

Seedling height and ground diameter: Three seedlings were randomly selected for each treatment, and their height and ground diameter growths were measured using a tape and Vernier caliper and recorded once a week.

Osmotic substances: Soluble sugar and starch contents were determined through anthrone colorimetry; soluble protein content was determined through Coomassie brilliant blue (G-250) staining; and proline content was determined through acid ninhydrin colorimetry [28].

Antioxidant systems: Malondialdehyde (MDA) content of leaves was determined using the 2-thiobarbituric acid (TBA) colorimetric method [29], whereas superoxide dismutase (SOD) activity was determined using the nitro blue tetrazolium (NBT) photoreduction method [30].

Soil enzyme activities: Acid phosphatase (S-ACP), polyphenol oxidase (S-PPO), urease (S-UE), and catalase (S-CAT) activities were determined using commercial kits (Beijing Solebo Biotechnology Co., Ltd.).

Soil available nitrogen/phosphorus/potassium (N/P/K): Available nitrogen(AN) content was quantified using the semi-micro Kelvin method. Available phosphorus (AP) content was quantified using the molybdenum-antimony anti-colorimetric method. Available potassium (AK) content was quantified using the flame photometric method [31].

Allelopathy index: Allelopathy index was calculated as follows: $\mathrm{RI}=(\mathrm{Ti}-\mathrm{To}) / \mathrm{To}$, where $\mathrm{To}$ is the control value and $\mathrm{Ti}$ is the treatment value of the test item; RI $>0$ represents the promotion effect; $\mathrm{RI}<0$ represents the inhibition effect; and the order of magnitude represents the intension, SE was 
determined as the arithmetic average of RI values of several test items measured by the donor on the same receptor [32,33].

\subsection{Statistical Analysis}

Microsoft Excel (2007) was used for preliminary statistics. SPSS 18.0 was used for further processing of experimental data. Two-way ANOVA was used to analyze significant differences in the effects of different concentrations of pericarp, leaf, and rhizosphere soil extracts on seed germination, seedling morphology, physiology, biochemistry, and soil enzyme activities of recipient plants. The significant level was $p<0.05$. Origin 9.1 (OriginLab Corporation, Northampton, MA, USA) was used to plot the data.

\section{Results}

\subsection{Effects of Aqueous Extracts of C. migao on L. formosana Seed Germination}

The germination rate and potential of L. formosana seeds gradually decreased with increase in concentrations of aqueous pericarp, leaf, and rhizosphere soil extracts. The decrease in L. formosana seed germination was low only under treatment with all concentrations of rhizosphere soil extracts (Figure 1). The germination rate and potential of L. formosana seeds treated with all C. migao extracts at concentrations of $>1 \mathrm{mg} \mathrm{mL}^{-1}$ were significantly different from those of $\mathrm{CK}(p<0.05)$. The germination rate and potential of L. formosana seeds were sharply decreased when the concentration of all extracts was $50 \mathrm{mg} \mathrm{mL}^{-1}$. The decrease in germination rate and potential of L. formosana seeds were the smallest when treated with $50 \mathrm{mg} \mathrm{mL}^{-1}$ aqueous rhizosphere soil extract, which reached $36.55 \%$ and $14.11 \%$, respectively.

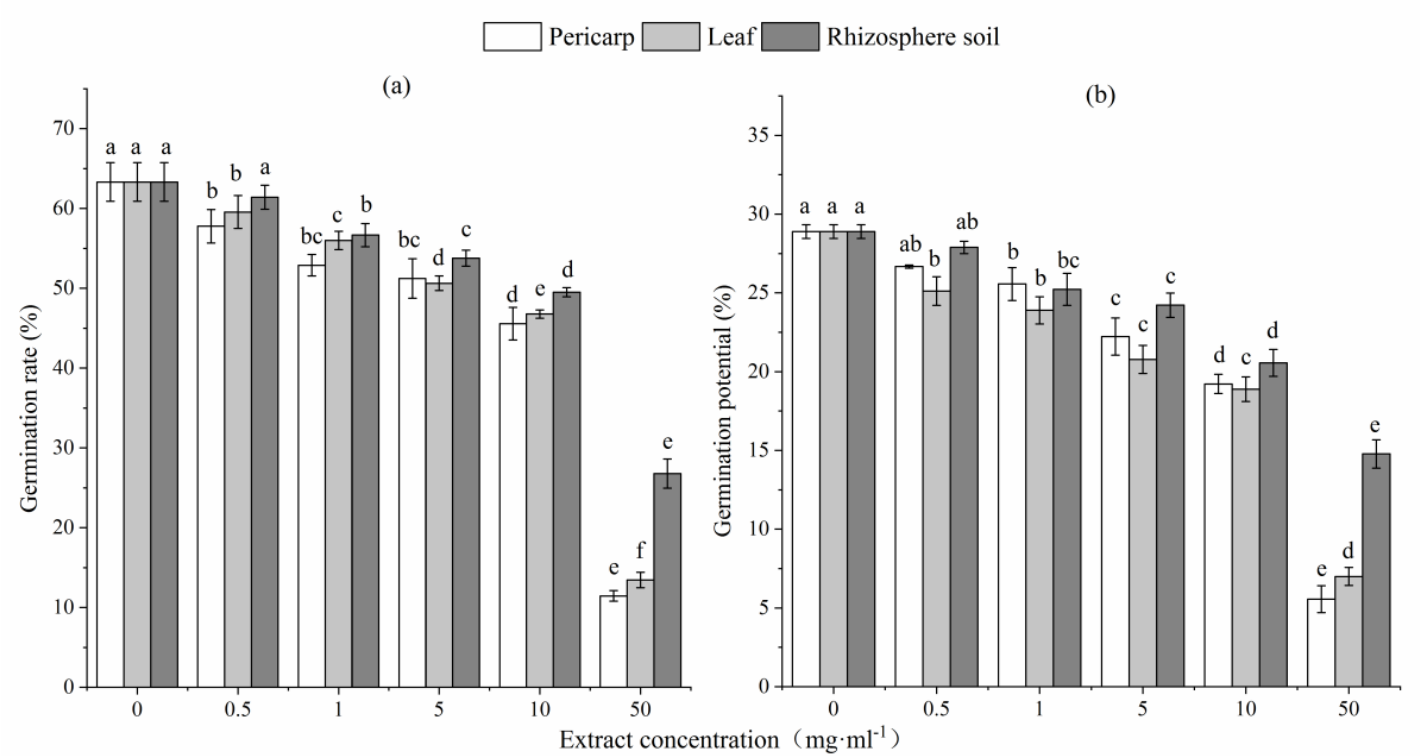

Figure 1. Germination rate (a) and potential (b) of L. formosana seeds following treatment with different concentrations of $C$. migao pericarp, leaf, and rhizosphere soil aqueous extracts. Lowercase letters represent significant differences in each treatment group $(p<0.05)$.

\subsection{Effects of Aqueous Extracts of C. migao on the Morphology of L. formosana Seedlings}

Seedling height and ground diameter of L. formosana increased initially and then decreased slowly with increased extract concentration, but even the lowest values remained higher than CK values (Figure 2). When the concentration of aqueous leaf and rhizosphere soil extract was 1-10 mg $\mathrm{mL}^{-1}$, the difference in height between treated seedlings and CK was significant $(p<0.05)$. When the 
concentration of aqueous pericarp extract was $0.5-1 \mathrm{mg} \mathrm{mL}^{-1}$, the difference in height between treated seedlings and CK was significant $(p<0.05)$. When the concentration of aqueous pericarp and rhizosphere soil extracts was $0.5 \mathrm{mg} \mathrm{mL}^{-1}$ and $10-50 \mathrm{mg} \mathrm{mL}^{-1}$, respectively, the difference in ground diameter between treated seedlings and CK was not significant $(p>0.05)$; however, this difference was significant after treatment with different concentration of aqueous leaf extract $(p<0.05)$.

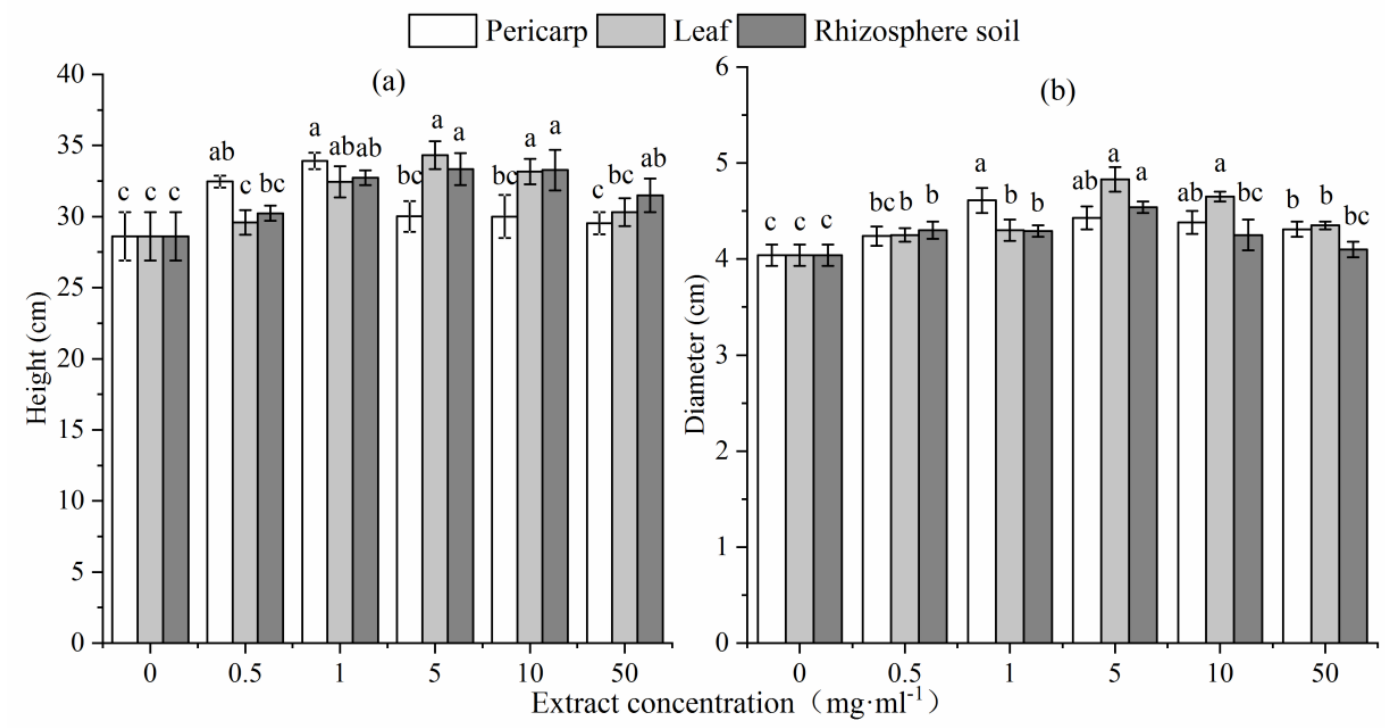

Figure 2. Height (a) and ground diameter (b) of L. formosana seedlings following treatment with different concentrations of $C$. migao pericarp, leaf, and rhizosphere soil aqueous extracts. Lowercase letters represent significant differences in each treatment group $(p<0.05)$.

\subsection{Effects of Aqueous Extracts C. Migao on Physiological and Biochemical Indices of L. formosana Seedlings}

The soluble protein content of L. formosana seedlings increased initially and then decreased with increase of the concentration of aqueous pericarp extract. The soluble protein content of L. formosana seedlings treated with at aqueous pericarp extract which was significantly higher than that of L. formosana seedlings treated with leaf and rhizosphere soil extracts $(p<0.05)$. The soluble protein content of $L$. formosana seedlings treated with at aqueous leaf extract at a concentration of 5-10 mg $\mathrm{mL}^{-1}$ was significantly higher than that of CK $(p<0.05)$. The soluble protein content of $L$. formosana seedlings treated with at aqueous rhizosphere soil at concentrations of $>1 \mathrm{mg} \mathrm{mL}^{-1}$ was significantly higher than that of CK $(p<0.05)$ (Figure 3).

The soluble starch content of L. fermonosa seedlings increased initially and then decreased with increase in concentration of aqueous leaf extract but remained significantly higher than that of $\mathrm{CK}$ $(p<0.05)$. When the concentration of leaf extract reached $10 \mathrm{mg} \mathrm{mL}^{-1}$, the soluble starch content was maximum $\left(0.50 \mathrm{mg} \mathrm{g}^{-1} \times \mathrm{FW}\right)$, which was twice as much as the $\mathrm{CK}$ value. When the concentration of aqueous pericarp extract was $50 \mathrm{mg} \mathrm{mL}^{-1}$, the soluble starch content of the treated seedlings was not significantly different from that of CK $(p>0.05)$; however, there was a significant difference between the other groups $(p<0.05)$. The soluble starch content of seedlings treated with aqueous rhizosphere soil extract at a concentration of $50 \mathrm{mg} \mathrm{mL}^{-1}$ was significantly higher than that of $\mathrm{CK}(p<0.05)$.

The soluble sugar content of seedlings was significantly higher than that of CK $(p<0.05)$ when the concentration of aqueous pericarp extract was $10 \mathrm{mg} \mathrm{mL}^{-1}$, and the highest content was achieved when extract concentration reached $50 \mathrm{mg} \mathrm{mL}^{-1}$. The soluble sugar content gradually decreased with increase in the concentration of aqueous extract leaf and rhizosphere soil extracts.

The proline content of $L$. formosana seedlings increased initially and then decreased with increase in the concentration of aqueous pericarp extract. When the concentration was $1-5 \mathrm{mg} \mathrm{mL}^{-1}$, the proline content of treated seedlings was significantly higher than that of CK $(p<0.05)$. The proline content of 
L. formosana seedlings increased with increase in the concentration of aqueous leaf and rhizosphere soil extracts. When the concentration of aqueous leaf extract reached $50 \mathrm{mg} \mathrm{mL}^{-1}$, the proline content of L. formosana seedlings reached the highest value $\left(297.20 \mu \mathrm{g} \times \mathrm{g}^{-1} \mathrm{FW}\right)$.
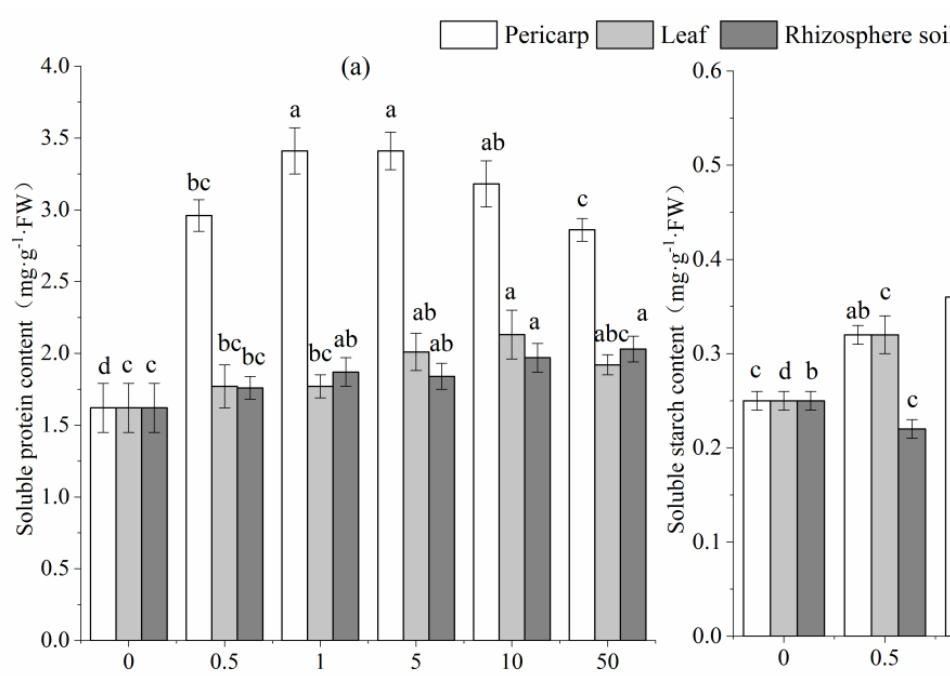

(b)
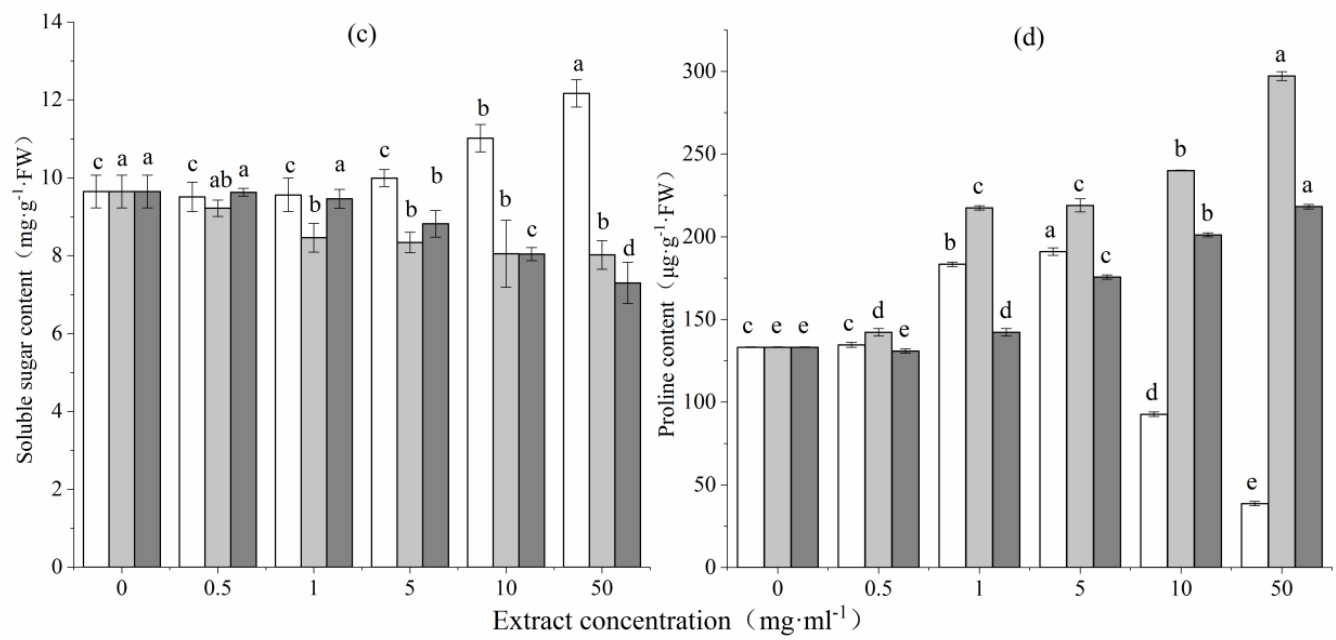

Figure 3. Soluble protein (a), soluble starch (b), soluble sugar (c), and proline (d) contents of L. formosana seedlings following treatment with different concentrations of C. migao pericarp, leaf, and rhizosphere soil aqueous extracts. Lowercase letters represent significant differences in each treatment group $(p<0.05)$.

The MDA content of L. formosana seedlings increased initially and then decreased with increase in the concentration of aqueous pericarp and leaf extracts. The MDA content of L. formosana seedlings treated with aqueous leaf extract was significantly higher than that seedlings treated with aqueous pericarp extract. When the concentration of aqueous leaf extract was $10 \mathrm{mg} \mathrm{mL}^{-1}$, the MDA content of treated seedlings was nearly 3.3 times that of CK. The MDA content $L$. formosana seedlings treated with all extracts at a concentration of $1 \mathrm{mg} \mathrm{mL}^{-1}$ was significantly different from that of $\mathrm{CK}(p<0.05)$ (Figure 4). 


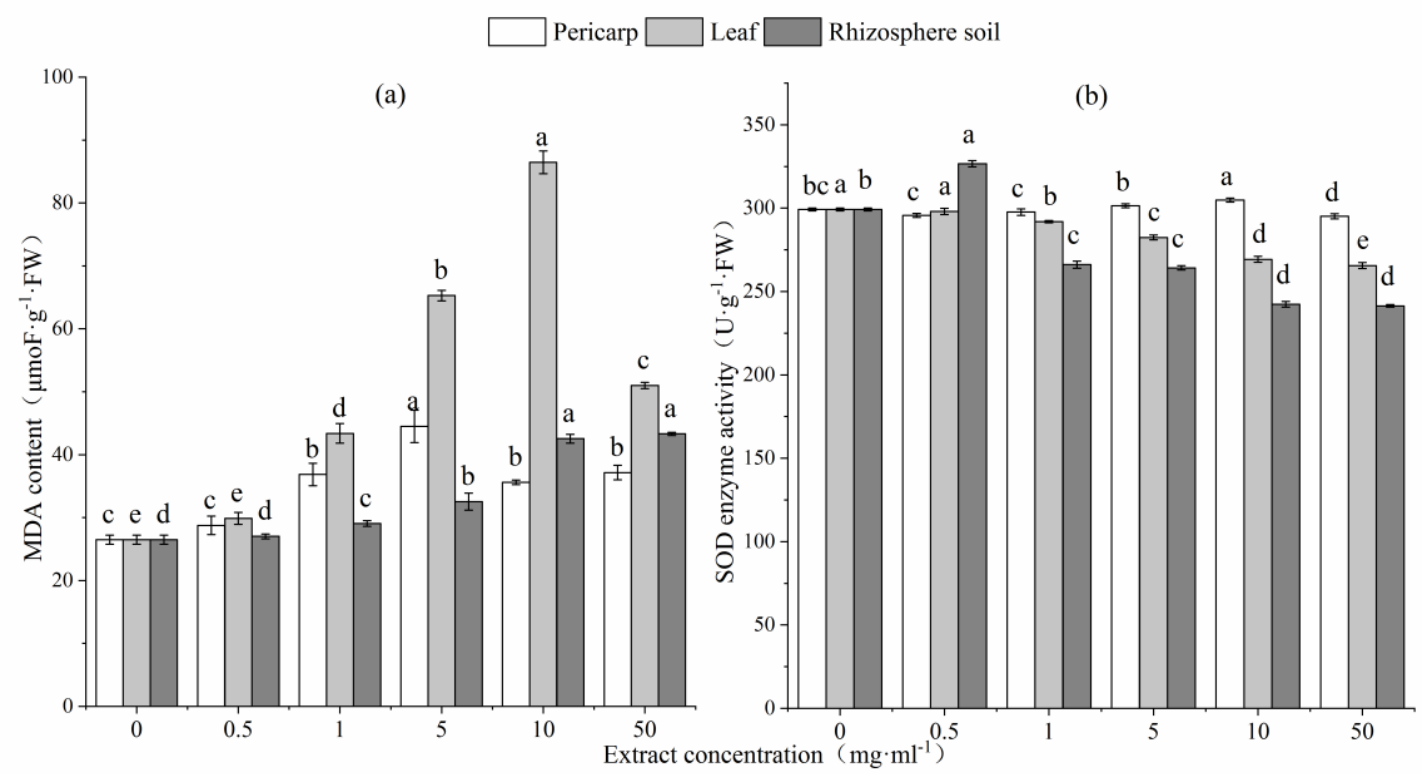

Figure 4. MDA content of (a) and SOD enzyme activity in (b) L. formosana seedlings following treatment with different concentrations of $C$. migao pericarp, leaf, and rhizosphere soil aqueous extracts. Lowercase letters represent significant differences in each treatment group $(p<0.05)$.

SOD activity in treated L. formosana seedlings was significantly higher than that in CK $(p<0.05)$ when the concentration of aqueous pericarp extract was $10 \mathrm{mg} \mathrm{mL}^{-1}$. SOD activity in L. formosana seedlings was significantly higher than that in CK $(p<0.05)$ when the concentration of aqueous rhizosphere soil extract was $0.5 \mathrm{mg} \mathrm{mL}^{-1}$, but it was significantly decreased at all other concentrations $(p<0.05)$. SOD activity in L. formosana seedlings decreased with increase in the concentration of aqueous leaf extract.

S-UE activity in treated L. formosana seedlings was significantly higher than that in CK $(p<0.05)$ after the concentration of aqueous pericarp extract was $1 \mathrm{mg} \mathrm{mL}^{-1}$. The highest S-UE activity was achieved when the concentration of aqueous pericarp extract was $5 \mathrm{mg} \mathrm{mL}^{-1}$. S-UE activity in treated seedlings was significantly higher than that in CK $(p<0.05)$ when the concentration of aqueous rhizosphere soil extract was $0.5-5 \mathrm{mg} \mathrm{mL}^{-1}$ (Figure 5).

S-PPO activity in L. formosana seedlings increased with increase in the concentration of aqueous pericarp and leaf extracts, and this activity remained significantly higher than that in CK $(p<0.05)$ when the concentration reached $1 \mathrm{mg} \mathrm{mL}^{-1}$ and $5 \mathrm{mg} \mathrm{mL}^{-1}$, respectively. S-PPO activity decreased with increase in the concentration of aqueous rhizosphere soil extract. When the concentration exceeded $1 \mathrm{mg} \mathrm{mL}^{-1}$, S-PPO activity in treated seedlings was significantly lower than that in CK $(p>0.05)$.

S-CAT activity gradually increased with increase in the concentration of aqueous pericarp and leaf extracts. When the concentration of aqueous pericarp and leaf extracts reached 5 and $1 \mathrm{mg} \mathrm{mL}^{-1}$, respectively, S-CAT activity in treated seedlings was significantly higher than that in CK $(p<0.05)$. S-CAT activity in seedlings treated with aqueous rhizosphere soil at concentrations of $>10 \mathrm{mg} \mathrm{mL}^{-1}$ was significantly higher than that in CK $(p<0.05)$.

S-ACP activity in L. formosana seedlings increased initially and then decreased with increase in the concentration of aqueous pericarp and rhizosphere soil extracts. When the concentration of aqueous pericarp and rhizosphere soil extracts was $0.5-5 \mathrm{mg} \mathrm{mL}^{-1}$ and $10 \mathrm{mg} \mathrm{mL}^{-1}$, respectively, S-ACP activity in treated seedlings was significantly higher than that in CK $(p<0.05)$. S-ACP activity in treated seedlings was significantly higher than that in CK $(p<0.05)$ when the concentration of aqueous leaf extract was $5 \mathrm{mg} \mathrm{mL}^{-1}$. The highest S-ACP activity was achieved following treatment with aqueous pericarp, leaf, and rhizosphere soil extracts at a concentration of $5 \mathrm{mg} \mathrm{mL}^{-1}$. 

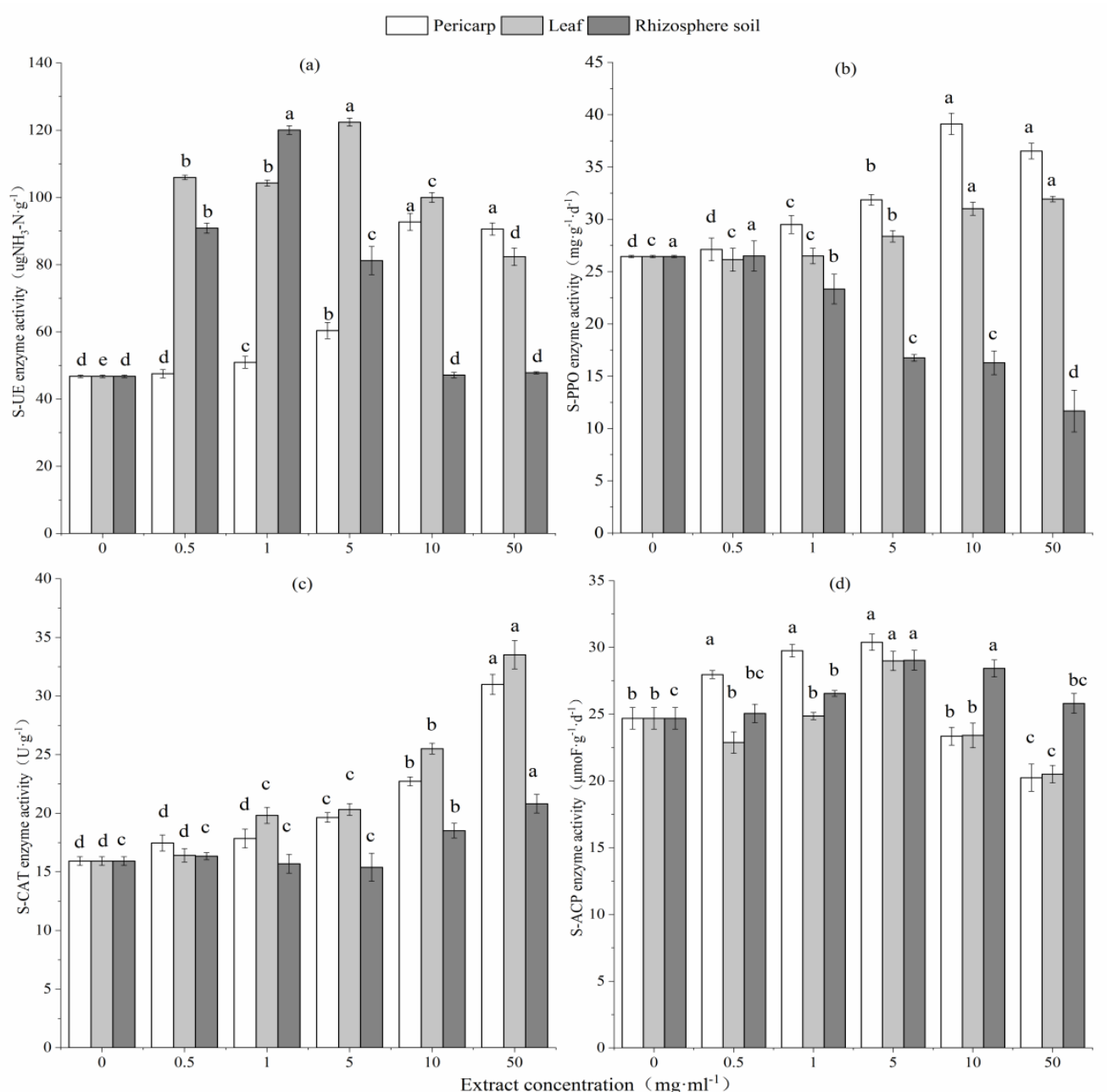

Figure 5. Activities of soil urease (S-UE) (a), polyphenol oxidase (S-PPO) (b), catalase (S-CAT) (c), and phosphatase (S-ACP) (d) in L. formosana seedlings following treatment with different concentrations of $C$. migao pericarp, leaf, and rhizosphere soil aqueous extracts. Lowercase letters represent significant differences in each treatment group $(p<0.05)$.

The contents of AN, AP, and AK in the soil of L. formosana seedlings did not show significant difference with CK under the concentration of extracts of $C$. migao $(p>0.05)$ (Table 1). AN content was the highest following treatment with aqueous pericarp extract at a concentration of $5 \mathrm{mg} \mathrm{mL}^{-1}$ and the lowest following treatment with aqueous leaf and soil rhizosphere extracts at a concentration of $50 \mathrm{mg} \mathrm{mL}^{-1}$. AP content was the highest following treatment with aqueous pericarp extract at a concentration of $5 \mathrm{mg} \mathrm{mL}^{-1}$. AK content was the highest following treatment with aqueous leaf extract at a concentration of $50 \mathrm{mg} \mathrm{mL}^{-1}$.

Table 1. AN, AP, and AK contents in the soil of L. formosana seedlings following treatment with different concentrations of aqueous extracts of C. migao pericarp, leaf, and rhizosphere soil.

\begin{tabular}{|c|c|c|c|c|}
\hline Part & Concentrations $\left(\mathrm{mg} \mathrm{mL}^{-1}\right)$ & $\mathrm{AN} / \mathrm{mg} \mathrm{kg}^{-1}$ & $\mathrm{AP} / \mathrm{mg} \mathrm{kg}^{-1}$ & $\mathrm{AK} / \mathrm{mg} \mathrm{kg}^{-1}$ \\
\hline \multirow{6}{*}{ Pericarp } & 0 & $74.91 \pm 3.24 \mathrm{a}$ & $7.91 \pm 0.38 a$ & $58.70 \pm 2.94 \mathrm{a}$ \\
\hline & 0.5 & $69.81 \pm 0.04 \mathrm{a}$ & $7.99 \pm 1.05 \mathrm{a}$ & $52.00 \pm 2.56 \mathrm{a}$ \\
\hline & 1 & $66.20 \pm 4.67 \mathrm{a}$ & $8.32 \pm 2.31 \mathrm{a}$ & $62.50 \pm 0.85 a$ \\
\hline & 5 & $76.34 \pm 2.82 \mathrm{a}$ & $8.03 \pm 2.15 a$ & $60.20 \pm 0.28 a$ \\
\hline & 10 & $74.32 \pm 2.30 \mathrm{a}$ & $7.89 \pm 1.80 \mathrm{a}$ & $58.65 \pm 1.05 \mathrm{a}$ \\
\hline & 50 & $64.46 \pm 2.61 \mathrm{a}$ & $7.53 \pm 2.53 a$ & $56.70 \pm 0.14 \mathrm{a}$ \\
\hline
\end{tabular}


Table 1. Cont.

\begin{tabular}{|c|c|c|c|c|}
\hline Part & Concentrations $\left(\mathrm{mg} \mathrm{mL}^{-1}\right)$ & $\mathrm{AN} / \mathrm{mg} \mathrm{kg}^{-1}$ & $\mathrm{AP} / \mathrm{mg} \mathrm{kg}^{-1}$ & $\mathrm{AK} / \mathrm{mg} \mathrm{kg}^{-1}$ \\
\hline \multirow{6}{*}{ Leaf } & 0 & $74.91 \pm 3.24 \mathrm{a}$ & $7.91 \pm 0.38 \mathrm{a}$ & $58.70 \pm 2.94 \mathrm{a}$ \\
\hline & 0.5 & $73.33 \pm 0.00 \mathrm{a}$ & $7.10 \pm 0.57 \mathrm{a}$ & $69.90 \pm 0.99 a$ \\
\hline & 1 & $63.98 \pm 5.33 \mathrm{a}$ & $9.48 \pm 1.83 \mathrm{a}$ & $65.00 \pm 4.79 a$ \\
\hline & 5 & $61.16 \pm 2.52 \mathrm{a}$ & $9.88 \pm 1.63 \mathrm{a}$ & $65.70 \pm 5.23 a$ \\
\hline & 10 & $60.00 \pm 3.26 \mathrm{a}$ & $9.12 \pm 1.02 \mathrm{a}$ & $73.25 \pm 3.26 \mathrm{a}$ \\
\hline & 50 & $59.35 \pm 4.74 \mathrm{a}$ & $8.06 \pm 0.96 a$ & $81.40 \pm 3.79 a$ \\
\hline \multirow{6}{*}{ Rhizosphere soil } & 0 & $74.91 \pm 3.24 \mathrm{a}$ & $7.91 \pm 0.38 \mathrm{a}$ & $58.70 \pm 2.94 \mathrm{a}$ \\
\hline & 0.5 & $73.37 \pm 3.10 \mathrm{a}$ & $8.20 \pm 1.05 a$ & $64.50 \pm 2.45 a$ \\
\hline & 1 & $67.98 \pm 3.57 \mathrm{ab}$ & $9.02 \pm 0.79 a$ & $70.50 \pm 1.86 \mathrm{a}$ \\
\hline & 5 & $67.77 \pm 2.46 \mathrm{ab}$ & $7.65 \pm 2.01 \mathrm{a}$ & $63.80 \pm 0.28 a$ \\
\hline & 10 & $62.65 \pm 2.86 \mathrm{ab}$ & $7.76 \pm 1.23 \mathrm{a}$ & $60.56 \pm 0.86 a$ \\
\hline & 50 & $52.38 \pm 3.98 b$ & $7.51 \pm 0.87 a$ & $55.80 \pm 4.84 \mathrm{a}$ \\
\hline
\end{tabular}

Note: Lowercase letters represent significant differences in each treatment group $(p<0.05)$.

\subsection{Allelopathic Effects of Aqueous Extracts of C. migao on L. formosana}

Eleven indicators (germination index, morphology, physiological and biochemical indices of seedlings, etc.) were used to analyze the allelopathy SE value to reflect the total allelopathic intensity of the C. migao pericarp, leaf, and rhizosphere soil at different concentrations on the target L. formosana (Figure 6).When all the extracts were at low and medium concentrations $\left(0.5-5 \mathrm{mg} \mathrm{mL}^{-1}\right)$, they promoted the growth of L. formosana. When the aqueous leaf extract concentration was $5 \mathrm{mg} \mathrm{mL}^{-1}$, the maximum value was 0.14 . When the concentration of the rhizosphere soil extract was $10 \mathrm{mg} \mathrm{mL}^{-1}$, the growth began to show slight inhibition. When the concentration of all extracts reached $50 \mathrm{mg} \mathrm{mL}^{-1}$, the inhibition effect was very obvious and reached the maximum value $(0.56)$ under the treatment of the pericarp extract. According to the synthetic allelopathic index, the comprehensive effect value of leaf extract liquefaction was significantly higher than that of the pericarp and rhizosphere soil.

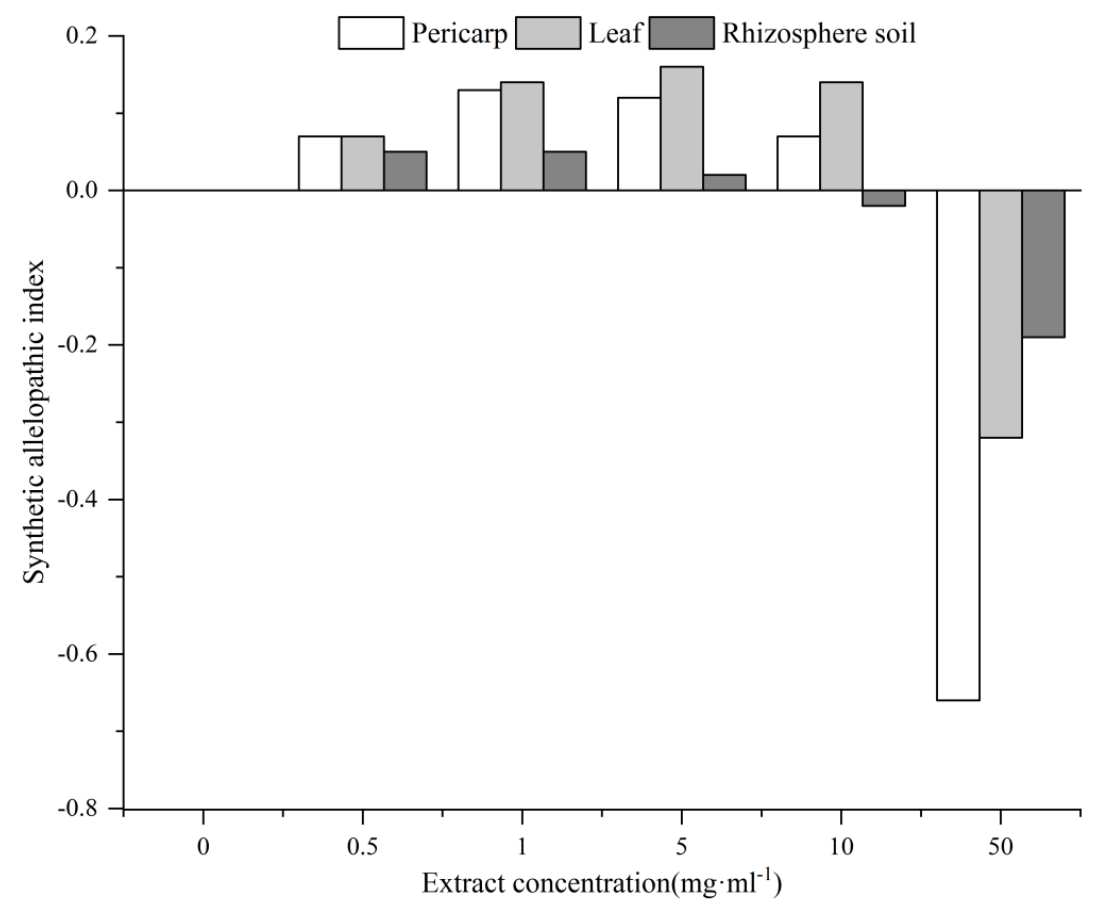

Figure 6. Allelopathic effects of $C$. migao pericarp, leaf, and rhizosphere soil aqueous extracts at different concentrations on L. formosana. 
The synthetic allelopathy effect (SE) was calculated as the average allelopathic index (RI) of all indicators with each treatment of L. formosana.

\section{Discussion}

Whether a plant can complete its regeneration in a forest often depends on whether the germination of its seeds of is inhibited by another plant. Seed germination rate of a plant could be a sensitive measure of the intensity of allelopathic activities of another plant [34], which influence the competitiveness and abundance of the recipient plants in a plant community [35]. Seed germination of L. formosana was inhibited to varying degrees by aqueous extracts of $C$. migao. The higher the concentration of the extracts, more robust was their inhibitory effect on seed germination of the recipient plants, which is consistent with previously reported trends [36-38]. When the concentration of all extracts increased to $50 \mathrm{mg} \mathrm{mL}^{-1}$, the germination rate and potential decreased rapidly. Similarly, the germination potential of L. formosana seeds exhibited a decreasing trend. These results indicated that the rate of germination of L. formosana seeds decreased, and the germination cycle was delayed. In addition, allelopathic substances appeared to affect the activities of key enzymes and substrates during the metabolism of $L$. formosana seeds, leading to seed deterioration. Reportedly, such factors play major roles in the emergence of $C$. migao as a dominant species. The seedling growth test is a biometric test for determining the initial growth and organogenesis of recipient plants; therefore, it is more effective for observing effects of allelochemicals and changes induced by them [39]. The height and ground diameter of $L$. formosana seedlings increased initially and then decreased slowly with increase in extract concentration, but even the lowest values were higher than $\mathrm{CK}$ values. This observation is consistent with the reports of Hossain and Weidenhamer [40,41]. Moreover, the results suggest that all extracts of different C. migao parts promoted the growth and development of L. formosana.

The physiological and ecological characteristics of dominant species are important for the survival and expansion of companion species in plant communities. High osmoregulatory capacity is a critical factor in plant interactions. Plants can reduce cell osmotic potential by increasing levels of osmotic regulators, such as soluble sugars and proteins, to adapt to external stressful environments. The soluble protein content of L. formosana seedlings significantly increased when the concentration of the aqueous leaf extract was $50 \mathrm{mg} \mathrm{mL}^{-1}$, after treatment with aqueous leaf and rhizosphere soil extract at a concentration of $1 \mathrm{mg} \mathrm{mL}^{-1}$ and all concentrations of aqueous pericarp extract, suggesting that the plants activated defense mechanisms, triggering the production of various enzymes to resist stress. The starch content of L. formosana seedlings significantly increased under stress. The above-mentioned treatments may have prevented starch hydrolysis, leading to gradual accumulation of starch and resulting in decreased soluble sugar content in seedlings [42,43]. Meanwhile, the change in the proline content of $L$. formosana seedlings increased with an increase in the concentration of the aqueous extract of $C$. migao leaf, and this increasing trend may help maintain the osmotic pressure in cells. There is a stable dynamic balance between active oxygen and the antioxidant system of dominant species and their associated species in plant communities. When exposed to external stress, membrane lipid peroxidation occurs. The degrees of stress and cell membrane lipid peroxidation are reflected by MDA content. Plants often minimize the damage caused by secondary metabolites, such as MDA, by altering SOD activity $[9,44,45]$. When the concentration of all extracts reached $1 \mathrm{mg} \mathrm{mL}^{-1}$, the MDA content of L. formosana seedlings increased significantly but the intensity of the effect gradually weakened. This could be a positive response of $L$. formosana to slight oxidative stress. However, when the stress level reached a certain threshold, excessive accumulation of reactive oxygen species resulted in the inhibition of SOD activity $[46,47]$. However, the SOD activity increased only when the concentration of aqueous pericarp and rhizosphere soil extracts was 10 and $0.5 \mathrm{mg} \mathrm{mL}^{-1}$, respectively, the other treatments inhibited the SOD activity, but the MDA content was elevated, indicating that the plasma membrane of $L$. formosana seedlings was damaged to varying degrees; however, $L$. formosana did not exhibit damage, indicating that these seedlings independently regulated stress levels through other antioxidant enzymes. 
In ecological environments, soil enzymes are important biological indicators of the quality of ecological environment and fertility of soil $[48,49]$, while S-UE, S-ACP, and invertase fundamentally reflect the transformation intensities of nitrogen, carbon, phosphorus, and potassium in soil. When the concentration of aqueous pericarp extract exceeded $1 \mathrm{mg} \mathrm{mL}^{-1}$, the concentration of aqueous rhizosphere soil extract was $0.5-5 \mathrm{mg} \mathrm{mL}^{-1}$, and the S-UE activity of all aqueous leaf extracts significantly increased S-PPO activity can promote the formation of soil humus. Following treatment with aqueous pericarp and leaf extracts at concentrations of 1 and $5 \mathrm{mg} \mathrm{mL}^{-1}$, respectively, S-PPO activity and soil fertility increased [50,51]. S-CAT activity indicates the rate of soil organic matter transformation and the intensity of humification. Similar, S-CAT activity was promoted to a certain extent following treatment with aqueous pericarp and leaf extracts at concentrations of 5 and $1 \mathrm{mg}$ $\mathrm{mL}^{-1}$, indicating that the extracts could promote the transformation of organic matter and increase organic matter content in L. formosana soil. S-ACP can promote the mineralization of phosphorus and improve the availability of soil phosphorus. S-ACP activity was the highest following treatment with all extracts at a concentration of $5 \mathrm{mg} \mathrm{mL}^{-1}$. Together, these results demonstrate that aqueous extracts of C. migao can facilitate nutrient recycling in L. formosana soil.

Furthermore, N, P, and K play important roles in soil fertility and can be described as the three elements for soil fertility. AN is one of the most effective forms of nitrogen in the soil and is one of the most depleted and limiting plant growth nutrients since it is easily soluble in water and is lost rapidly [52]. AP is a bottleneck factor for vegetation growth, and its content represents the amount that plants can absorb in the current season [53]. AK is a direct indicator of soil fertility, which also promotes early plant root formation and growth as well as improves plant adaptability. In this experiment, we found that the content of $\mathrm{AN}, \mathrm{AP}$, and $\mathrm{AK}$ in the soil of L. formosana seedlings did not change significantly under different aqueous extracts treatment. The results show that the enhance effects are not induced by the fertilizer.

The synthetic allelopathic index can adequately reflect the allelopathic intensity of $C$. migao. The allelopathic comprehensive effect value of aqueous leaf extract treatment is significantly higher than that of pericarp and rhizosphere soil. Because all types of organic substances synthesized via photosynthesis are initially stored in leaves, they may contain more allelochemicals and at higher concentrations [25], thereby enhancing the allelopathic effect of C. migao. When all the extracts were at low and medium concentrations $\left(0.5-5 \mathrm{mg} \mathrm{mL}^{-1}\right)$, they promoted the growth of L. formosana, Although allelopathy is generally considered an inhibitory mechanism [54,55], numerous studies have shown both promoting and inhibitory effects of aqueous plant products on the growth and development of surrounding plants via various mechanisms [56-60]. In this study, the aqueous C. migao extracts inhibited the growth of $L$. formosana when extracts concentration reached $50 \mathrm{mg} \mathrm{mL}^{-1}$. However, L. formosana grows well in the natural state. Perhaps, under the natural elution condition, the concentration of each extract did not reach a high level, or was affected by the complex environment around, and did not inhibit the growth and development of L. formosana.

\section{Conclusions}

Under different concentrations of C. migao pericarp, leaf, and rhizosphere soil extract, the germination index, seedling morphological indexes, and physiological and biochemical indexes of the saplings were different, thereby reflecting the close relationship between the allelopathic intensity and the leaching site and concentration. Under the treatment with low and medium concentration of extracts from the $C$. migao pericarp, leaf, and rhizosphere soil, the germination rate, and seed potential of $L$. formosana were reduced to some extent, and the position of $C$. migao as the dominant species was well regulated. In the seedling stage, the extracts of $C$. migao increased the rate of nutrient recycling in soil, enhanced the permeability of organelle membranes, influenced the physiological activities of cells or the transport of substances, thereby increasing height and ground diameter of L. formosana. Such complex interactions may be the important reasons underlying the long-term co-existence of 
C. migao and its companion species L. formosana, which is ultimately conducive to maintain the stability of the forest ecosystems.

Author Contributions: J.L., and D.W. designed the experiments, J.C., X.X., and S.W. participated in the experiment, help to complete the experiments and analyzed the data. S.W. revised the article.

Funding: This research was funded by National Natural Science Foundation of China, "Plasticity and its variability of plants in response to the heterogeneity of key environmental factors in karst habitats" (NSFC 31800335), Guizhou Science and Technology Program "Research on the Development and Use of Guizhou Characteristic Medicinal Plants such as Ginger Fruit and Tripterygium Wilfordii" (SY [2015] 3023), Guizhou Science and Technology Program "Source Screening and Mycorrhizal Seedling Breeding Technology of Cinnamomum migao "(Qiankehe Supporting [2019] 2774), and Ecology Domestic First-Class Discipline Construction Program (GNYL2017-007 to SW).

Acknowledgments: The author would like to thank all the authors for their help in the experiment, especially Shu Wang and Jingzhong Chen, for their constant and reliable assistance in plant cultivation and physiological and biochemical analysis.

Conflicts of Interest: The authors declare no conflict of interest.

\section{References}

1. Einhellig, F.A. Allelopathy: Current status and future goals. In Allelopathy: Organisms, Processes, and Applications/Inderjit; Dakshini, K.M.M., Einhellig, F.A., Eds.; Acs. Sym. Ser. American Chemical Society: Washington, DC, USA, 1995; pp. 1-25.

2. Das, R.; Geethangili, M.; Majhi, A.; Das, B.; Rao, Y.K.; Tzeng, Y.M. A new highly oxygenated pseudoguaianolide from a collection of the flowers of Parthenium hysterophorus. Chem. Pharm. Bull. 2005, 53, 861-862. [CrossRef] [PubMed]

3. Rice, E.L. Allelopathy, 2nd ed.; Academic Press: New York, NY, USA, 1984.

4. Callaway, R.M.; Aschehoug, E.T. Invasive plants versus their new and old neighbors: Amechanism for exotic invasion. Science 2000, 290, 521-523. [CrossRef] [PubMed]

5. Meiners, S.J.; Kong, C.-H.; Ladwig, L.M.; Pisula, N.L.; Lang, K.A. Developing an ecological context for allelopathy. Plant Ecol. 2012, 213, 1861-1867. [CrossRef]

6. Yu, L.Z.; Yu, L.F.; Li, K.Z.; Callaway, R.M.; Valiente-Banuet, A.; Du, Q.L. Integrating novel chemical weapons and evolutionarily increased competitive ability in success of a tropical invader. New Phytol. 2015, 205, 1350-1359.

7. Fernandez, C.; Monnier, Y.; Santonja, M.; Gallet, C.; Weston, L.A.; Bernard, P. The impact of competition and allelopathy on the trade-off between plant defense and growth in two contrasting tree species. Front. Plant Sci. 2016, 7, 1-14. [CrossRef] [PubMed]

8. Raskin, I. Role of salicylic acid in plants. Annu. Rev. Plant Physiol. Plant Mol. Biol. 1992, 43, $439-463$. [CrossRef]

9. Weiner, J. Plant allelochemical interference or soil chemical ecology? Perspect. Plant Ecol. 2001, 4, 3-12.

10. Bais, H.P.; Vepachedu, R.; Gilroy, S.; Callaway, R.M.; Vivanco, J.M. Allelopathy and exotic plant invasion: From molecules and genes to species interactions. Sci. 2003, 301, 1377-1380. [CrossRef]

11. Cheema, Z.A.; Farooq, M.; Wahid, A. Role of allelopathy during the invasion process by alien invasive plants in terrestrial ecosystems. In Allelopathy; Lorenzo, P., Hussain, M.I., Luís, G., Lorenzo, P., Hussain, M.I., González, Á.L., Eds.; Springer: Berlin, Germany, 2013; pp. 3-21.

12. Nickerson, K.; Flory, S.L. Competitive and allelopathic effects of the invasive shrub Schinus terebinthifolius (Brazilian peppertree). Biol. Invasions. 2015, 17, 555-564. [CrossRef]

13. Zhiqun, T.; Jian, Z.; Junli, Y.; Chunzi, W.; Danju, Z. Allelopathic effects of volatile organic compounds from Eucalyptus grandis rhizosphere soil on Eisenia fetida assessed using avoidance bioassays, enzyme activity, and comet assays. Chemosphere 2017, 173, 307-317. [CrossRef]

14. Mittler, R. Oxidative stress, antioxidants and stress tolerance. Trends Plant Sci. 2002, 7, 405-410. [CrossRef]

15. Liang, Y.C.; Chen, Q.; Liu, Q.; Zhang, W.; Ding, R. Exogenous silicon (Si) increase antioxidant enzyme activity and reduces lipid peroxidation in roots of salt-stressed barley (Hordeum vulgare L.). J. Plant Physiol. 2003, 160, 1157-1164. [CrossRef] [PubMed]

16. Zhang, Z.Y.; Yin, W.J.; Li, J.; Du, J.F.; Yang, Y.H.; Chen, X.J.; Lin, W.X. Physio-ecological properties of continuous cropping Rehmannia glutinosa. Chin. J. Plant Ecol. 2010, 34, 547-554. 
17. Gill, S.S.; Tuteja, N. Reactive oxygen species and antioxidant machinery in abiotic stress tolerance in crop plants. Plant Physiol. Bioch. 2010, 48, 909-930. [CrossRef] [PubMed]

18. Veal, E.; Day, A. Hydrogen peroxide as a signaling molecule. Antioxid. Redox. Sign. 2011, 15, 147-151. [CrossRef] [PubMed]

19. Kreslavskll, V.D.; Los, D.A.; Allakhverdiev, S.I.; Kuznetsov, V.V. Signaling role of reactive oxygen species in plants under stress. Russ. J. Plant. Physl. 2012, 59, 141-154. [CrossRef]

20. Gimingham, C.H. Calluna and its associated species: Some aspects of co-existence in communities. Veg. 1978, 6, 179-186. [CrossRef]

21. Longpré, M.H.; Bergeron, Y.; Paré, D.; Béland, M. Effect of companion species on the growth of jack pine (Pinus banksiana). Can. J. Forest. Res. 1994, 24, 1846-1853. [CrossRef]

22. Legare, S.; Bergeron, Y.; Pare, D. Effect of aspen (Populus tremuloides) as a companion species on the growth of black spruce (Picea mariana) in the southwestern boreal forest of Quebec. For. Eco. Manag. 2005, 208, $211-222$. [CrossRef]

23. Li, L.X. Study on Cinnamomum migao Population Characteristics in Guizhou; Guizhou University: Guiyang, China, 2016.

24. Bagamboula, C.F.; Uyttendaele, M.; Debevere, J. Inhibitory effect of thyme and basil essential oils, carvacrol, thymol, estragol, linalool and p-cymene towards Shigella sonenei and S. flexneri. Food Microbiol. 2004, 21, 33-42. [CrossRef]

25. Zhao, L.C. Study on the Chemieal Constituents of Cinnamomum migao; Guizhou University of Traditional Chinese Medicine: Guiyang, China, 2007.

26. Wang, R.L.; Peng, S.L.; Zeng, R.S.; Ding, L.W.; Xu, Z.F. Cloning, expression and wounding induction of $\beta$ caryophyllene synthase gene from Mikania fnicrantha H.B.K. and allelopathic potential of $\beta$-caryophyllene. Allelopath. J. 2009, 24, 35-44.

27. Chi, X.J.; Liu, M.; Ou, G.T.; Wen, A.H.; Liao, X.F. Allelopathy of aqueous extracts from Cinnamomum migao H.W.Li on Blumea balsamifera L.DC. Guangdong Agric. Sci. 2014, 41, 21-24.

28. Li, H.S. Experimental Principles and Techniques of Plant. Physiology and Biochemistry; Higher Education Press: Beijing, China, 2000.

29. Hodges, D.M.; DeLong, J.M.; Forney, C.F.; Prange, R.K. Improving the thiobarbituric acid-reactive-substances assay for estimating lipid peroxidation in plant tissues containing anthocyanin and other interfering compounds. Planta 1999, 207, 604-611. [CrossRef]

30. Zou, Q. Instruction for Plant Physiology Experiments; China Agricultural Publishing House: Beijing, China, 2000.

31. Lu, R.K. Soil Argrochemistry Analysis Protocoes; China Agriculture Sc.: Beijing, China, 1999.

32. Williamson, G.B.; Richardson, D. Bioassays for allelopathy: Measuring treatment responses with independent controls. J. Chem. Ecol. 1988, 14, 181-187. [CrossRef] [PubMed]

33. Chauhan, B.S.; Abugho, S.B. Interaction of rice residue and PRE herbicides on emergence and biomass of four weed species. Weed Technol. 2012, 26, 627-632. [CrossRef]

34. Chiapusio, G.; Sanchez, A.M.; Reigosa, M.J.; Gonzalez, L.; Pellissier, F. Do germination indices adequately reflect allelochemical effects on the germination process? J. Chem. Ecol. 1997, 23, 445-453. [CrossRef]

35. Wang, Y.; Fu, L.; Long, F.L.; Liu, Y.; Zhao, D.H.; Li, L. Allelopathic effects of water extractions from two Veronica species on 6 kinds of receiving crops. J. Northwest A.F. Univ. 2013, 41, 178-190.

36. Chon, S.U.; Choi, S.K.; Jung, S.; Jang, H.G.; Pyo, B.S.; Kim, S.M. Effects of Alfalfa leaf extracts and phenolic allelochemicals on early seedling growth and root morphology of Alfalfa and Barnyard grass. Crop. Prot. 2002, 21, 1077-1082. [CrossRef]

37. Kaushal, R.; Verma, K.S.; Singh, K.N. Effects of Grewia optiva and Populus deltoids leachates on field crops. Allelopath. J. 2003, 11, 229-234.

38. Dai, Z.C.; Wang, X.Y.; Qi, S.S.; Du, D.L. Effects of leaf litter on inter-specific competitive ability of the invasive plant Wedelia trilobata. Ecol. Res. 2016, 31, 367-374. [CrossRef]

39. Blum, K. Effects of ferulie acid and allelopathic compound on net P, K, and water uptake by cumuber seedlings in a split-root system. J. Chem. Ecol. 1990, 16, 455-463.

40. Hossain, M.K.; Dhali, M.A.H.; Hossain, M.S. Effects of forest soil and leaf-litter on germination and initial seedling growth of Leucaena leucocephala. Allelopath. J. 2002, 10, 13-20.

41. Weidenhamer, J.D. New approaches for the analyse of allelochemicals in soil. Allelopath. J. 2007, 19, 135-142. 
42. Shikanai, T. Regulation of photosynthetic electron transport. BBA-Bioenerg. 2011, 1807, 375-383. [CrossRef] [PubMed]

43. Zhang, Y.; Yao, Q.; Li, J.; Hu, Y.; Chen, J. Growth response and nutrient uptake of Eriobotrya japonica plants inoculated with three isolates of arbuscular mycorrhizal fungi under water stress condition. J. Plant. Nutr. 2014, 37, 690-730. [CrossRef]

44. Ding, J.; Sun, Y.; Xiao, C.L.; Shi, K.; Zhou, Y.H.; Yu, J.Q. Physiological basis of different allelopathic reactions of Cucumber and Figleaf gourd plants to cinnamic acid. J. Exp. Bot. 2007, 58, 3765-3773. [CrossRef] [PubMed]

45. Nathan, C.; Ding, A. Reactive Oxygen Intermediates. Cell 2010, 140, 951. [CrossRef]

46. Zhang, F.J.; Guo, J.Y.; Liu, W.X.; Wan, F.H. Influence of coastal plain yellowtops (Flaveria bidentis) residues on growth of cotton seedlings and soil fertility. Arch. Agron. Soil Sci. 2012, 58, 1117-1128. [CrossRef]

47. Zhang, K.M.; Shen, Y.; Fang, Y.M.; Liu, Y. Changes in gametophyte physiology of Pteris multifida induced by the leaf leachate treatment of the invasive Bidens pilosa. Environ. Sci. Pollut. R. 2016, 23, 1-8. [CrossRef]

48. Giallfreda, L.; Salmino, F.; Vtoallte, A. Pesticide effects on the activity of free, immobillized and intertase. Soil Biol. Bicohem. 1995, 27, 1201-1208. [CrossRef]

49. Tabatabai, M.A.; Dick, W.A. Research and developments in measuring activities. In Enzymes in Soil; Burns, R.G., Dick, R.P., Eds.; Marcel Dekker Inc.: New York, NY, USA, 2002; pp. 567-596.

50. Yakushev, A.V.; Kuznetsova, I.N.; Blagodatskaya, E.V.; Blagodatsky, S.A. Temperature dependence of the activity of polyphenol peroxidases and polyphenol oxidases in modern and buried soils. Eurasian Soil Sci. 2014, 47, 459-465. [CrossRef]

51. Fan, D.; Fan, K.; Zhang, D.; Zhang, M.; Wang, X. Impact of fertilization on soil polyphenol dynamics and carbon accumulation in a tea plantation, Southern China. J. Soil Sediment. 2016, 17, 1-10. [CrossRef]

52. Batish, D.R.; Singh, H.P.; Pandher, J.K.; Arora, V.; Kohli, R.K. Phytotoxic effect of Parthenium residues on the selected soil properties and growth of chickpea and radish. Weed Biol Manag. 2002, 2, 73-78.

53. Zhou, L.C.; Chen, X.M.; Li, X.L.; Yang, X.Q.; Xia, W. Study on Variation of Available Phosphorus of Soil in Karst Regions Under Rocky Desertification, Southwest China. J. Earth Sci. Environ. 2009, 31, 418-422.

54. Inderjit, D.A.; Karban, R.; Callaway, R.M. The ecosystem and evolutionary contexts of allelopathy. Trends. Ecol. Evol. 2011, 26, 655-662. [CrossRef]

55. Rout, M.E.; Chrzanowski, T.H.; Smith, W.K.; Gough, L. Ecological impacts of the invasive grasssorghum halepenseon native tallgrass prairie. Biol. Invasions. 2013, 15, 327-339. [CrossRef]

56. Alam, S.M.; Ala, S.A.; Azmi, A.R. Influence of aqueous leaf extract of purple nutsedge (Cyperus rotundus L.) and $\mathrm{Nacl}$ on germination and seeding growth of wheat (Triticum aestivum L.). Pak. J. Sci. Ind. Res. 1999, 42, 372-373.

57. Padhy, B.; Patnaik, P.K.; Tripathy, A.K. Allelopathic potential of Eucalyptus leaf litter leachates on germination and seedling growth of Fingemillet. Allelopath. J. 2000, 7, 69-78.

58. Benvenuti, S.; Dinelli, G.; Bonetti, A. Germination ecology of Leptochloa chinensis: A new weed in the Italian rice agro-environment. Weed Res. 2004, 44, 87-96. [CrossRef]

59. Kong, C.H.; Wang, M.L.; Wang, P.; Han, W.N.; Xiang, R.M. Reproduction allocation and potential mechanism of individual allelopathic rice plants in the presence of competing Barnyardgrass. Pest. Manag. Sci. 2013, 69, 142-148. [CrossRef]

60. Christoph, K.; Markus, S.; Roland, G. Weed suppression and early sugar beet development under different cover crop mulches. Plant. Prot. Sci. 2017, 52, 1-7. [CrossRef]

(C) 2019 by the authors. Licensee MDPI, Basel, Switzerland. This article is an open access article distributed under the terms and conditions of the Creative Commons Attribution (CC BY) license (http://creativecommons.org/licenses/by/4.0/). 